\title{
PRODUÇÃO DE SERAPILHEIRA E APORTE DE NUTRIENTES EM AREAS DE FLORESTA ATLÂNTICA EM SANTA MARIA DE JETIBÁ, ES ${ }^{1}$
}

\section{LITTER PRODUCTION AND NUTRIENT ADDITION IN ATLANTIC FOREST AREAS IN SANTA MARIA DE JETIBÁ, ES}

\author{
Geângelo Petene Calvi ${ }^{2} \quad$ Marcos Gervasio Pereira $^{3} \quad$ Ademar Espíndula Júnior $^{4}$ \\ RESUMO
}

Este estudo foi realizado na Fazenda Espíndula, Santa Maria do Jetibá, ES, com o objetivo de avaliar a deposição de serapilheira e o aporte de nutrientes em áreas com diferentes estádios sucessionais. Foram selecionadas duas áreas com formações vegetais distintas: Floresta Secundária (FS) com cerca de 25 ha, correspondente a uma antiga área de cultivo de mandioca a cerca de 50 anos em processo de sucessão ecológica e onde hoje se encontra uma mata secundária e Floresta Secundária Antiga (FSA) que corresponde a uma área de floresta que foi submetida apenas extração seletiva de madeira para utilização da própria fazenda. Em cada uma das formações vegetais, foram delimitadas áreas de aproximadamente 0,1 ha e, nestas, foram distribuídos aleatoriamente dez coletores cônicos. As coletas foram realizadas mensalmente durante o período de novembro de 2003 a outubro de 2005. O material após secagem foi estratificado, avaliando-se o total aportado, a contribuição das diferentes frações e a entrada de nutrientes. Não foram verificadas diferenças significativas entre o total aportado entre as áreas, sendo os maiores valores de produção, $5,70 \mathrm{Mg}$ ha $^{-1}$ (FS) e 5,73 $\mathrm{Mg} \mathrm{ha}^{-1}$ (FSA) observados no verão, possivelmente por causa da ação mecânica de ventos e da chuva. A fração de maior contribuição foi a foliar, correspondendo a 74,62\% para a área de Floresta Secundária e 69,46\% para a área de Floresta Secundária Antiga.

Palavras-chaves: ciclagem de nutrientes; floresta secundária; matéria orgânica.

\section{ABSTRACT}

This study was accomplished on Espíndula Farm, Santa Maria de Jetibá (ES), with the objective of evaluating the litter and nutrients deposition in areas with different succession stadiums. Two areas were selected with different vegetable coverings, defined as: (SF) Secondary Forest, with about 25 ha of area, corresponding to an old area of cassava cultivation with about 50 years in process of ecological succession and where today there is a secondary forest and an Old Secondary Forest (OSF) corresponding to a forest area that has just been submitted to a selective wood extraction for use of the farm itself. In each one of vegetal areas, approximately 0.1 ha was delimited and in these ten conical collectors were randomized distributed. The litter collections were accomplished monthly from November 2003 to October 2005. After drying, the material was stratified and the total contributed and the contribution of the different fractions, and the nutritious addition were evaluated. It was not verified significant differences among the total of litter deposited among the areas, being the highest production values observed in the summer, $5.70 \mathrm{Mg} \mathrm{ha}^{-1}$ (SF) and $5.73 \mathrm{Mg} \mathrm{ha}^{-1}(\mathrm{OSF})$, possibly due to the winds and rain mechanical action. The fraction of higher contribution was the foliar, corresponding to $74.62 \%$ for the SF area and $69.46 \%$ for the OSF area

Keywords: nutrient cycling; secondary forest; organic matter.

\section{INTRODUÇÃO}

$\mathrm{O}$ estudo da ciclagem de nutrientes minerais é fundamental para o conhecimento da estrutura e funcionamento de ecossistemas florestais. Parte do processo de retorno de matéria orgânica e de nutrientes para o solo florestal se dá por meio da produção de serapilheira, sendo considerada o meio mais importante de transferência de elementos essenciais da vegetação para o solo (VITAL, et al., 2004). Define-se

1. Parte da monografia do primeiro autor apresentada ao Instituto de Florestas da UFRRJ, como requisito parcial para a obtenção do grau de Engenheiro Florestal

2. Engenheiro Florestal, Mestre em Ciências de Florestas Tropicais pelo Instituto Nacional de Pesquisas da Amazônia (INPA), Departamento de Silvicultura Tropical, Av. Efigênio Salles, 2239, CEP 69060-001, Manaus (AM). gpcalvi@yahoo.com.br

3. Engenheiro Agrônomo, Professor Associado II, Departamento de Solos, Universidade Federal Rural do Rio de Janeiro, BR 465 km 7, CEP 23890-000, Seropédica (RJ). Bolsista do CNPq. gervasio@ufrrj.br

4. Engenheiro Agrônomo, Mestre em Agronomia pelo Curso de Pós-Graduação em Agronomia - Ciência do Solo, Universidade Federal Rural do Rio de Janeiro, BR 465 km 7, CEP 23890-000, Seropédica (RJ).

Recebido para publicação em 22/03/2006 e aceito em 15/05/2009. 
serapilheira como sendo o material recém-caído, na parte superficial do piso da floresta, constituído por folhas, caules, ramos, frutos, flores e outras partes da planta, bem como restos de animais e material fecal. Assim que é depositada sobre o solo, a serapilheira é submetida a um processo de decomposição que se inicia com a ação da fauna edáfica constituída, sobretudo de artrópodes, que têm como principal função a degradação do material para que este seja posteriormente decomposto pelos microorganismos e, ao final do processo, haja a liberação gradativa dos nutrientes minerais que são constituintes dos tecidos orgânicos (GOLLEY et al., 1978).

Dessa forma, o material orgânico que é depositado continuamente sobre o solo assume importância indiscutível na manutenção da fertilidade e dos níveis de nutrientes no solo, uma vez que a serapilheira assume o papel de estoque potencial de nutrientes para o sistema.

Segundo estudos realizados por Bray e Gorham (1964), Morellato (1992), Figueiredo Filho, et al.(2003), entre outros, a serapilheira é composta, de maneira geral, de 60 a $80 \%$ de folhas, 1 a $15 \%$ de ramos e 1 a $25 \%$ de casca, embora alguns autores tenham encontrado valores menores que este, como Fassbender e Grim (1981) que, estudando uma Floresta Ttropical Úmida de montanha na Venezuela, encontraram um percentual de $48,49 \%$ da serapilheira composta pela fração folhas.

Diversos fatores bióticos e abióticos afetam a produção de serapilheira, tais como: tipo de vegetação, altitude, latitude, precipitação, temperatura, regimes de luminosidade, relevo, deciduidade, estádio sucessional, disponibilidade hídrica e características do solo. Dependendo das características de cada ecossistema, um determinado fator pode prevalecer sobre os demais.

De acordo com Bray e Gorham (1964), Mason (1980), temperaturas elevadas e maior quantidade de insolação constituem-se nos fatores climáticos mais relevantes para a produção da serapilheira. Já Martins e Rodrigues (1999), estudando a produção de serapilheira em clareiras de uma floresta estacional semidecidual no município de Campinas, SP, verificaram que a velocidade dos ventos pode atuar como o fator mais relevante na produção de serapilheira. Haag (1985) sugere que, além das condições climáticas, o ciclo biológico da vegetação existente no local afeta consideravelmente a quantidade de serapilheira produzida.

Diversos estudos têm sido realizados no Brasil e no mundo com o intuito de contribuir para o melhor conhecimento sobre a ciclagem de nutrientes e a dinâmica dos ecossistemas florestais e até mesmo em plantios homogêneos de espécies florestais e agrícolas (MURBACH et al., 2003; GARAY et al., 2003), a fim de determinar os padrões que cada tipologia vegetal apresenta para tal processo e as diferenças existentes entre elas, possibilitando assim um melhor entendimento do mecanismo e as respostas do ambiente para modificações antrópicas realizadas no meio.

Delitti (1984) mencionou dois padrões básicos para a deposição anual de serapilheira. O primeiro se refere a uma maior deposição na época seca, como ocorre em ecossistemas amazônicos, nas florestas mesófilas e cerrados e está diretamente ligado à quantidade e disponibilidade de água no solo que, nessa época, tende a ser reduzida em tais ambientes, causando um estresse hídrico e, conseqüentemente, a senescência do vegetal, aumentando assim a quantidade de material aportado. O segundo caso é o contrário e consiste em um aumento na intensidade de deposição de serapilheira na época úmida, típico das florestas atlânticas e restingas, estando ligado ao impacto mecânico provocado pelas chuvas e os ventos, provocando um aumento na taxa de deposição.

Estudando a produção de serapilheira e retorno de nutrientes em uma floresta pluvial atlântica (Floresta Ombrófila Densa), Custódio Filho et al. (1996) registraram uma produção anual de $6.054,10 \mathrm{~kg} \mathrm{ha}^{-1}$ de serapilheira, sendo que a fração folhas contribuiu com $72,73 \%$ do total, os ramos com $16,09 \%$ e outros componentes com 11,29\%. Durigan et al. (1996), estudando a produção de folhedo em mata ciliar, registraram um período de alta produção de serapilheira no final do inverno e início da primavera.

Este trabalho teve como objetivo quantificar a produção da serapilheira e o aporte de nutrientes em áreas de floresta Atlântica em diferentes estádios sucessionais. 


\section{MATERIAL E MÉTODOS}

\section{Localização e caracterização da área de estudo}

O estudo foi realizado na Fazenda Espíndula, situada no município de Santa Maria de Jetibá, Espírito Santo. O relevo da região é montanhoso na maior parte da região, na área de estudo o solo foi classificado como Cambissolo Háplico. O clima é tropical de altitude, tipo Cwb segundo a classificação de Köppen, com temperaturas variando entre 7,3 a $9,4{ }^{\circ} \mathrm{C}$ nos meses mais frios e 25,3 a $27,8{ }^{\circ} \mathrm{C}$ nos meses mais quentes. A altitude da região fica em torno de $1.050 \mathrm{~m}$ acima do nível médio dos mares. O índice pluviométrico chega a $1.700 \mathrm{~mm} \mathrm{ano}^{-1}$.

Para a caracterização climática da área foram utilizados os dados do balanço hídrico do município de Domingos Martins, ES, do website da Incaper (Instituto Capixaba de Pesquisa, Assistência Técnica e Extensão Rural - http://www.incaper.es.gov.br). A área onde está localizada a estação coletora de dados se encontra próxima à fazenda, o que justifica a utilização dos dados climatológicos. A vegetação predominante na região é a Floresta Tropical Ombrófila Densa.

Foram selecionadas duas áreas com formações vegetais distintas em relação ao estádio sucessional, distante, uma da outra, cerca de $2 \mathrm{~km}$, definidas como: Floresta Secundária (FS), com cerca de 25 ha, correspondente a uma antiga área de cultivo de mandioca a cerca de 50 anos em processo de sucessão ecológica e onde hoje se encontra uma mata secundária e Floresta Secundária Antiga (FSA) que corresponde a uma área de floresta que foi submetida apenas à extração seletiva de madeira para utilização da própria fazenda.

A matriz onde as áreas estudadas estão inseridas é caracterizada por plantações de hortaliças como, repolho, cebola, alho, gengibre, entre outras. Há também áreas habitadas bem próximas às áreas de estudo, com presença de diversas estradas, galpões, residências e área de lazer.

\section{Produção de serapilheira}

Em cada uma das formações vegetais foi delimitada uma área de aproximadamente 0,1 ha, e, nestas, foram distribuídos aleatoriamente dez coletores cônicos de $0,25 \mathrm{~m}^{2}$. Os coletores foram afixados nas árvores com fios de nylon a aproximadamente $1,0 \mathrm{~m}$ de altura. A serapilheira depositada foi coletada mensalmente durante o período de novembro de 2003 a outubro de 2005. Após ser coletado o material foi estratificado em: folhas, ramos, material reprodutivo e outros (frações não identificáveis). Após a triagem o material foi seco em estufa à temperatura de $\left(65^{\circ} \mathrm{C} \pm 5\right)$ por 48 horas, sendo posteriormente pesado a fim de avaliar a contribuição de cada fração no aporte total do material decíduo. equação:

A produção de serapilheira foi estimada segundo Lopes et al. (2002) tomando por base a seguinte

$\mathrm{PAS}=($ PMS $\times 10.000) / \mathrm{Ac}$

Em que PAS = Produção média anual de serapilheira $\left(\mathrm{kg} \mathrm{ha}^{-1}\right.$ ano); PMS = Produção média mensal de serapilheira $\left(\mathrm{kg} \mathrm{ha}^{-1} \mathrm{mês}\right) ; \mathrm{Ac}=$ Área do coletor $\left(\mathrm{m}^{2}\right)$.

Após essa etapa, o material decíduo foi homogeneizado, obtendo-se uma amostra que foi triturada em moinho tipo Willey e submetida à digestão sulfúrica (TEDESCO et al., 1995). No extrato, foram determinados os conteúdos de nitrogênio $(\mathrm{N})$ por destilação por arraste a vapor, fósforo $(\mathrm{P})$ por colorimetria e potássio $(\mathrm{K})$ por fotometria de chama.

Partindo-se dos teores e da quantidade de material depositado, foram quantificados os conteúdos de $\mathrm{N}, \mathrm{P}$ e K adicionados mensalmente.

\section{RESULTADOS E DISCUSSÃO}

No período estudado (novembro de 2003 a outubro de 2005), a produção total de serapilheira foi de $5,70 \mathrm{Mg} \mathrm{ha}^{-1}$ para a área de Floresta Secundária (FS) e 5,73 $\mathrm{Mg} \mathrm{ha}^{-1}$ para a área de Floresta Secundária Antiga (FSA). No ano 1 (nov/03 a out/04), a produção da FS e FSA foi, respectivamente, 2,72 e 2,93 $\mathrm{Mg} \mathrm{ha}^{-}$ ', enquanto no ano 2 (nov/04 a out/05) a deposição total foi igual de 2,98 e 2,80 $\mathrm{Mg} \mathrm{ha}^{-1}$, para a FS e FSA respectivamente, não sendo verificada diferença estatística entre as áreas.

De acordo com a literatura (GOLLEY et al., 1978), a quantidade de serapilheira aportada em florestas tropicais de todo o mundo varia ente 4 e $25 \mathrm{Mg} \mathrm{ha}^{-1}$. Em média, nas florestas tropicais sobre solos 
de baixa fertilidade verificam-se depósitos de 7,5 $\mathrm{Mg} \mathrm{ha}^{-1}$ de matéria seca na forma de resíduos orgânicos formadores da serapilheira, enquanto em solos de fertilidade média essa produção é de $10,5 \mathrm{Mg} \mathrm{ha}^{-1}$ e em áreas montanhosas de 6,3 $\mathrm{Mg} \mathrm{ha}^{-1}$ (ANDRADE et al., 1999).

Estudando a produção de serapilheira em áreas de floresta semidecídua com diferentes graus de perturbação, Werneck et al. (2001) encontraram maiores valor de deposição para as áreas mais preservadas, sendo que esse valor diminuía com o aumento do grau de perturbação da floresta. Segundo os autores, embora trechos mais perturbados tenham um maior número de espécies pioneiras, a produção de serapilheira nessas áreas também poderia estar relacionada à proporção ocupada pelas copas, de modo que, quanto maiores forem às árvores, maiores serão as proporções ocupadas pelas copas e, consequentemente, maior será a produção de serapilheira.

Assim, a abundância das espécies pioneiras pode ser menos importante que o tamanho e o porte do dossel na determinação da produção da serapilheira (SONGWE et al., 1988) o que pode explicar o comportamento similar das áreas estudadas. Através de observações de campo, verificou-se uma grande quantidade de árvores pioneiras que apresentavam portes semelhantes, com indivíduos de médio porte predominando nos estratos e poucos indivíduos de grande porte.

Citando vários autores, Leitão Filho et al. (1993) destacam o papel das espécies pioneiras na produção de serapilheira por terem rápido crescimento e ciclo de vida curto, investindo pesadamente na produção de biomassa em curto espaço de tempo, sendo precoce nas fenofases reprodutivas com grandes produções de flores e frutos. Dessa forma, espera-se que a produção de serapilheira seja mais expressiva para áreas ainda em desenvolvimento sucessional, em razão da existência das espécies pioneiras. Esse comportamento foi observado pelos mesmos autores em trechos sucessionais iniciais em um trecho de floresta atlântica em Cubatão (SP), porém esse padrão não foi observado no presente estudo.

Quanto à deposição mensal na área FS, o mês que apresentou menor produção de serapilheira foi o mês de outubro de 2004 com produção total no valor de $0,85 \mathrm{Mg} \mathrm{ha}^{-1}$ e o mês de maior deposição, foi janeiro de 2005 com valor de $3,98 \mathrm{Mg} \mathrm{ha}^{-1}$ de material decíduo. Já para a área FSA, o mês de menor deposição de serapilheira foi julho de 2005 no qual foi aportado um total de $0,97 \mathrm{Mg} \mathrm{ha}^{-1}$ e o mês de outubro de 2005 foi o que apresentou maior valor com 4,50 $\mathrm{Mg} \mathrm{ha}^{-1}$.

Foi verificado que entre os meses de novembro a janeiro, que é o período úmido, há um aumento na deposição de serapilheira e na época mais seca do ano, que ocorre entre abril a junho, há uma redução na deposição do material decíduo. Segundo Delitti (1984), o aumento na intensidade de deposição de serapilheira na época úmida é típico das florestas atlânticas, o que pode explicar o maior aporte nesse período.

Em relação às estações, foi observada significância (pela análise de variância) apenas para a fração folhas e total de serapilheira depositada em ambas as áreas nos dois anos de estudo. Também foi verificada significância para a fração ramos na área FSA no segundo ano de estudo (Tabelas 1 e 2).

No primeiro ano de estudo, para FS, verificou-se uma maior quantidade da fração foliar sendo depositada na estação do verão, diferindo estatisticamente das demais. Foi observado o mesmo comportamento para o total de serapilheira depositada (Tabela 1).

Para a área FSA, os maiores valores da fração foliar foram observados nas estações da primavera e do verão. Porém, o mesmo comportamento não foi verificado para o total de serapilheira depositada, onde as maiores quantidades de material ocorreram nas estações verão e outono (Tabela 1). 
TABELA 1: Massa $\left(\mathrm{Mg} \mathrm{ha}^{-1}\right)$ dos diferentes estratos da serapilheira no primeiro ano de estudo (novembro/2003 a outubro/2004).

TABLE 1: Mass $\left(\mathrm{Mg} \mathrm{ha}^{-1}\right)$ of different strata of litter in the first year of study (from November/2003 to October /2004).

\begin{tabular}{l|cc|c|c|c|cc}
\hline \multicolumn{10}{c}{ Floresta Secundária } \\
\hline Estação & Folhas & Galhos & Mat. Rep. & Outros & \multicolumn{2}{c}{ Total } \\
\hline Verão & 0,24 & $\mathrm{~A}$ & $*$ & $*$ & $*$ & 0,33 & $\mathrm{~A}$ \\
Outono & 0,12 & $\mathrm{~B}$ & $*$ & $*$ & $*$ & 0,17 & $\mathrm{~B}$ \\
Inverno & 0,13 & $\mathrm{~B}$ & $*$ & $*$ & $*$ & 0,18 & $\mathrm{~B}$ \\
Primavera & 0,15 & $\mathrm{~B}$ & $*$ & $*$ & $*$ & 0,22 & $\mathrm{~B}$ \\
\hline \multicolumn{8}{c}{ Floresta Secundária Antiga } \\
\hline Estação & Folhas & Galhos & Mat. Rep. & Outros & \multicolumn{2}{c}{ Total } \\
\hline Verão & 0,23 & $\mathrm{~A}$ & $*$ & $*$ & $*$ & 0,32 & $\mathrm{~A}$ \\
Outono & 0,10 & $\mathrm{~B}$ & $*$ & $*$ & $*$ & 0,31 & $\mathrm{~A}$ \\
Inverno & 0,10 & $\mathrm{~B}$ & $*$ & $*$ & $*$ & 0,18 & $\mathrm{~B}$ \\
Primavera & 0,24 & $\mathrm{~A}$ & $*$ & $*$ & $*$ & 0,17 & $\mathrm{~B}$ \\
\hline
\end{tabular}

Médias seguidas da mesma letra na coluna, não diferem por Tukey a $5 \%$ de significância; * não apresentou significância pelo teste F. Mat. Rep. = Material Reprodutivo

Para o segundo ano do estudo, na área FS, foi observada maior deposição da fração folhas na estação do verão, deferindo significativamente pelo teste Tukey a $5 \%$ de significância, das demais estações. $\mathrm{O}$ mesmo comportamento foi verificado para o total do material depositado (Tabela 2).

$\mathrm{Na}$ área FSA a maior deposição da fração folhas ocorreu na primavera, seguida do verão. O menor valor de deposição foi observado no inverno. A estação do outono apresentou valores intermediários entre estas últimas (Tabela 2).

Por meio dos dados apresentados na Tabela 2, para a fração galhos, verifica-se que as estações de maior deposição foram o verão e a primavera. A menor deposição ocorreu no inverno e a estação do outono apresentou deposição intermediária entre as demais estações. Para o total de material decíduo depositado na área FSA no segundo ano de estudo, foram observados maiores valores no verão e na primavera, seguidos pelo outono. A menor produção de serapilheira ocorreu no inverno (Tabela 2).

TABELA 2: Massa $\left(\mathrm{Mg} \mathrm{ha}^{-1}\right)$ dos diferentes estratos da serapilheira no segundo ano de estudo (novembro/2004 a outubro/2005).

TABLE 2: Mass $\left(\mathrm{Mg} \mathrm{ha}^{-1}\right)$ of different strata of litter in the second year of study (from November/2004 to October /2005).

\begin{tabular}{|c|c|c|c|c|c|c|c|c|}
\hline & \multicolumn{8}{|c|}{ Floresta Secundária } \\
\hline Estação & \multicolumn{2}{|c|}{ Folhas } & \multicolumn{2}{|c|}{ Galhos } & Mat. Rep. & Outros & \multicolumn{2}{|c|}{ Total } \\
\hline Verão & 0,26 & $\mathrm{~A}$ & \multicolumn{2}{|c|}{$*$} & \multicolumn{2}{|l|}{$*$} & 0,34 & $\mathrm{~A}$ \\
\hline Outono & 0,16 & B & \multicolumn{2}{|c|}{ * } & \multicolumn{2}{|l|}{ * } & 0,21 & $\mathrm{~B}$ \\
\hline Inverno & 0,17 & B & \multicolumn{2}{|c|}{ * } & \multicolumn{2}{|l|}{ * } & 0,21 & B \\
\hline Primavera & 0,18 & B & \multicolumn{2}{|c|}{$*$} & \multicolumn{2}{|l|}{$*$} & 0,23 & B \\
\hline & \multicolumn{8}{|c|}{ Floresta Secundária Antiga } \\
\hline Estação & \multicolumn{2}{|c|}{ Folhas } & \multicolumn{2}{|c|}{ Galhos } & Mat. Rep. & Outros & \multicolumn{2}{|c|}{ Total } \\
\hline Verão & 0,18 & $\mathrm{~B}$ & 0,05 & $\mathrm{~A}$ & $*$ & $*$ & 0,26 & $\mathrm{AB}$ \\
\hline Outono & 0,08 & $\mathrm{BC}$ & 0,03 & $\mathrm{AB}$ & $*$ & $*$ & 0,22 & $\mathrm{~B}$ \\
\hline Inverno & 0,08 & $\mathrm{C}$ & 0,02 & $\mathrm{~B}$ & * & $*$ & 0,12 & $\mathrm{C}$ \\
\hline Primavera & 0,27 & A & 0,05 & A & * & * & 0,34 & A \\
\hline
\end{tabular}

Médias seguidas da mesma letra na coluna, não diferem por Tukey a $5 \%$ de significância; * não apresentou significância pelo teste F. Mat. Rep. = Material Reprodutivo

Segundo os dados apresentados nas Tabelas 1 e 2, observa-se que a área de Floresta Secundária apresentou o mesmo padrão de deposição nos dois anos de estudo, o que não foi verificado para a área de Floresta Secundária Antiga.

Estudando a produção de serapilheira em Floresta Ombrófila Mista, em São Francisco de Paula, RS, 
Backes et al. (2005) encontraram maior taxa de produção de material decíduo durante a primavera e a menor durante o inverno. Quantificando o aporte de serapilheira em sucessão ecológica de um ecossistema da Floresta Ombrófila Densa das Terras Baixas, na Floresta Estadual do Palmito, município de Paranaguá/PR, Pinto e Marques (2003) também encontraram uma maior taxa de deposição de serapilheira no período mais úmido (primavera e verão) e uma menor produção no período mais seco do ano (inverno).

A contribuição da fração folhas foi diferenciada para as áreas estudadas. Foi observada uma maior predominância dessa fração na área FS onde tal fração foi responsável por cerca de $75 \%$ do total de serapilheira produzida, enquanto na FSA sua contribuição esteve em torno de 69\% (Tabela 3). Esses dados são corroborados pelos verificados por Bray e Gorham (1964), Morellato, (1992), Figueiredo Filho et al. (2003), Toledo e Pereira, (2004), que afirmam que 60 a 80\% da serapilheira é composta pela fração folhas. As frações galhos e outros não apresentaram comportamento diferenciado com relação às duas áreas estudadas (Tabela 3).

A fração material reprodutivo foi mais expressiva na área de floresta Secundária Antiga correspondendo em média nos dois anos a 7,33\% da serapilheira produzida, enquanto na área de Floresta Secundária, essa fração contribuiu com cerca de $4,40 \%$ do total de biomassa aportado (Tabela 3). Tal variação pode estar ligada aos tipos de frutos e sementes existentes em cada área. Em observações feitas durante as triagens da serapilheira, constatou-se que na área FSA havia maior quantidade de frutos carnosos, típicos de espécies secundárias e climáxicas, enquanto na área de Floresta Secundária a fração frutos era composta, predominantemente, por frutos e sementes de dispersão anemocórica, típico de espécies pioneiras apresentando, geralmente, menor peso que os demais tipos de sementes, embora sejam produzidas em maiores quantidades.

TABELA 3: Contribuição das diferentes frações da serapilheira nas áreas de Floresta Secundária e Floresta Secundária Antiga, em Santa Maria de Jetibá, ES.

TABLE 3: Litter different fractions contribution in the Secondary Forest and Old Secondary Forest areas, in Santa Maria do Jetibá, ES.

\begin{tabular}{|c|c|c|c|c|c|c|c|c|}
\hline \multirow[b]{3}{*}{ Fração } & \multicolumn{4}{|c|}{ Floresta Secundária } & \multicolumn{4}{|c|}{ Floresta Secundária Antiga } \\
\hline & \multicolumn{2}{|c|}{ Ano 1} & \multicolumn{2}{|l|}{ Ano 2} & \multicolumn{2}{|c|}{ Ano 1} & \multicolumn{2}{|l|}{ Ano 2} \\
\hline & Total $\left(\mathrm{Mg} \mathrm{ha}^{-1}\right)$ & $\%$ & Total $\left(\mathrm{Mg} \mathrm{ha}^{-1}\right)$ & $\%$ & Total $\left(\mathrm{Mg} \mathrm{ha}^{-1}\right)$ & $\%$ & Total $\left(\mathrm{Mg} \mathrm{ha}^{-1}\right)$ & $\%$ \\
\hline Folhas & 1,96 & 72,06 & 2,30 & 77,18 & 2,03 & 69,28 & 1,95 & 69,64 \\
\hline Ramos & 0,49 & 18,01 & 0,41 & 13,76 & 0,53 & 18,09 & 0,45 & 16,07 \\
\hline Mat. Rep. & 0,14 & 5,15 & 0,11 & 3,69 & 0,21 & 7,17 & 0,21 & 7,50 \\
\hline Outros & 0,13 & 4,78 & 0,16 & 5,37 & 0,16 & 5,46 & 0,19 & 6,79 \\
\hline Total & 2,72 & 100,00 & 2,98 & 100,00 & 2,93 & 100,00 & 2,80 & 100,00 \\
\hline
\end{tabular}

Quanto aos testes estatísticos, para todas as variáveis estudadas houve distribuição normal, porém os dados não apresentaram significância na ANOVA, o que impediu a realização dos testes de média.

\section{Conteúdo de nutrientes}

Os teores de nutrientes adicionados em cada uma das áreas são apresentados nas Tabelas 4 e 5 . As maiores adições de $\mathrm{N}$ e $\mathrm{K}$ foram verificadas na área FSA estando esses valores associados às maiores quantidades de serapilheira depositada nestas áreas. Para o $\mathrm{P}$ não foram observadas diferenças na adição deste nutriente entre as áreas.

Comparando-se as áreas estudadas quanto à adição de nitrogênio pela deposição da serapilheira, percebe-se que, na Floresta Secundária, a entrada desse nutriente para o sistema foi um pouco inferior a encontrada na área de Floresta Secundária Antiga (Tabelas 4 e 5). 
TABELA 4: Conteúdo de Nitrogênio (N), Fósforo (P) e Potássio (K), expressos em $\mathrm{kg} \mathrm{ha}^{-1}$ ano $^{-1}$, para a Floresta Secundária, em Santa Maria de Jetibá, ES.

TABLE 4: Nitrogen (N), Phosphorus (P) and Potassium (K) contents, expressed in $\mathrm{kg} \mathrm{ha}^{-1} \mathrm{year}^{-1}$ to Secondary Forest area in Santa Maria de Jetibá, ES.

\begin{tabular}{lcc|c}
\hline Fração & $\mathrm{N}$ & $\mathrm{P}$ & $\mathrm{K}$ \\
\hline Folhas & 29,16 & 1,79 & 5,45 \\
Galhos & 4,59 & 0,37 & 0,94 \\
Mat. Reprodutivo & 1,75 & 0,11 & 0,50 \\
Outros & 2,68 & 0,12 & 0,44 \\
\hline Total & 38,18 & 2,39 & 7,35 \\
\hline
\end{tabular}

Quanto ao potássio, os valores variaram entre $5,45 \mathrm{~kg} \mathrm{ha}^{-1} \mathrm{ano}^{-1}$ e $8,82 \mathrm{~kg} \mathrm{ha}^{-1} \mathrm{ano}^{-1}$. Esses valores foram inferiores aos verificados em outras florestas tropicais (GOLLEY et al., 1978; SAMPAIO et al., 1988; TOLEDO et al., 2002) e plantios homogêneos (ANDRADE et al., 2000; COSTA et al., 2004). Não foram constadas diferenças na adição de fósforo entre as áreas, sendo que os valores variaram de $1,79 \mathrm{~kg} \mathrm{ha}^{-1} \mathrm{ano}^{-1}$ na área de Floresta Secundária a $1,66 \mathrm{~kg} \mathrm{ha}^{-1} \mathrm{ano}^{-1}$ na área de Floresta Secundária Antiga, sendo tais valores mais baixos que os observados em outras florestas tropicais (GOLLEY et al., 1978, UNESCO, 1978). Para ambas as florestas o conteúdo de nutrientes adicionados obedeceu à seguinte ordem decrescente foi $\mathrm{N}>\mathrm{K}$ > P.

TABELA 5: Conteúdo de Nitrogênio (N), Fósforo (P) e Potássio (K), expressos em $\mathrm{kg} \mathrm{ha}^{-1}$ ano $^{-1}$, para a Floresta Secundária Antiga, no município de Santa Maria de Jetibá, ES.

TABLE 5: Nitrogen (N), Phosphorus (P) and Potassium (K) contents, expressed in $\triangleq \mathrm{kg} \mathrm{ha}^{-1} \mathrm{year}^{-1}$ to Old Secondary Forest area in Santa Maria de Jetibá, ES.

\begin{tabular}{l|c|c|c}
\hline Fração & $\mathrm{N}$ & $\mathrm{P}$ & $\mathrm{K}$ \\
\hline Folhas & 27,46 & 1,66 & 8,82 \\
Galhos & 6,24 & 0,40 & 0,94 \\
Mat. Reprodutivo & 3,10 & 0,18 & 0,58 \\
Outros & 3,35 & 0,15 & 0,47 \\
\hline Total & 40,16 & 2,39 & 10,81 \\
\hline
\end{tabular}

\section{CONCLUSÕES}

Com base nesses resultados, pode-se concluir a existência de um equilíbrio entre as áreas, de forma que, a área de Floresta Secundária, com apenas 50 anos de processo sucessional, apresenta, em relação à produção de serapilheira e aporte de nutrientes, comportamento similar a uma área de floresta onde só houve exploração de madeira como atividade antrópica, no caso, a área de floresta secundária antiga.

\section{REFERÊNCIAS BIBLIOGRÁFICAS}

ANDRADE, A. G.; CABALLERO, S. S. U.; FARIA, S. M. Ciclagem de nutrientes em ecossistemas florestais. Rio de Janeiro: Embrapa Solos, 1999. 22 p. (Documentos, 13).

ANDRADE, A. G.; COSTA, G. S.; FARIA, S. M. Decomposição e deposição da serapilheira em povoamentos de Mimosa caesalpiniifolia, Acacia mangium e Acacia holosericea com quatro anos de idade em Planossolo. Revista Brasileira de Ciência do Solo, Viçosa, v. 24, n. 4, p.777-785, jul./ago. 2000.

BACKES A.; PRATES F. L.; VIOLA M. G. Produção de serapilheira em Floresta Ombrófila Mista, em São Francisco de Paula, Rio Grande do Sul, Brasil. Acta Botânica Brasilica, Porto Alegre, v 19, n. 1, p. 155-160, jan./abr. 2005.

BRAY, J.R.; GHORAN, E. Litter production in forest of the world. Advances Ecology of Research, v.2, p.101-157, 1964.

COSTA G. S. et al. Aporte de nutrientes pela serapilheira em uma área degradada e revegetada com leguminosas arbóreas. Revista Brasileira de Ciência do Solo, Viçosa, v. 28. n. 5, p.919-927, set./out. 2004.

CUSTÓDIO FILHO, A. et al. Produção de serapilheira e o retorno de macronutrientes em floresta pluvial atlântica Estação Biológica de Boracéia (São Paulo - Brasil). Revista do Instituto Florestal, São Paulo, v. 8, n. 1, p.1-16, 
jan./jun.1996.

DELITTI, W. B. C. Aspectos comparativos da ciclagem de nutrientes minerais na mata ciliar, no campo cerrado e na floresta implantada de Pinus elliottii Engelm var. elliottii (Mogi-Guaçu, SP). 1984. 132 f. Tese (Doutorado em Biociências) - Universidade de São Paulo. Instituto de Biociências, São Paulo.

DURIGAN, G.; LEITÃO FILHO, H. F.; PAGANO, S. N. Produção de folhedo em matas ciliares na região oeste do Estado de SP. Revista do Instituto Florestal, São Paulo, v. 8, n. 2, p. 187-199, jul./dez. 1996.

FASSBENDER, H. W.; GRIM, U. Ciclos bioquímicos en un ecosistema florestal de los Andes Occidentales de Venezuela. II - Produción y decomposición de los residuos vegetales. Turrialba, San Jose, v. 31, n. 1, p. 39-47, ene/mar. 1981.

FIGUEIREDO FILHO, A. et al. Avaliação estacional da deposição de serapilheira em uma floresta ombrófila mista localizada no sul do estado do Paraná. Ciência Florestal, Santa Maria, v. 13, n. 1, p. 11-18, jul./dez. 2003.

GARAY, I. et al. Comparação da matéria orgânica e de outros atributos do solo em plantações de Acacia mangium E Eucalyptus grandis. Revista Brasileira de Ciência do Solo, Viçosa, v. 27, n. 4, p.705-712, jul./ago. 2003.

GOLLEY, F. B. et al. Ciclagem de minerais em um ecossistema de floresta tropical úmida. São Paulo: Pedagógica e Universitária, 1978. 256 p.

HAAG, H. P. Ciclagem de nutrientes em florestas tropicais. Campinas: Fundação Cargill, 1985. 144 p.

LEITÃO-FILHO, H. F. et al. Ecologia da Mata Atlântica em Cubatão. São Paulo: Ed. da UNESP; Campinas: Ed. da UNICAMP, 1993.

LOPES, M. I. S.; DOMINGOS, M.; STRUFFALDI-DE VUONO, Y. Ciclagem de nutrientes minerais. In: SYSLVESTRE, L. S.; ROSA, M. M. T. Manual metodológico para estudos botânicos na mata atlântica. Seropédica: EDUR - UFRRJ, 2002. p.72-102.

MARTINS, S. V.; RODRIGUES, R. R. Produção de serrapilheira em clareiras de uma floresta estacional semidecidual no município de Campinas, SP. Revista Brasileira de Botânica, São Paulo, v. 22, n. 3, p. 405-412, set./dez. 1999.

MASON, C. F. Decomposição. São Paulo: Ed. Da Universidade de São Paulo. 1980. 63 p. (Temas de Biologia, 18).

MORELLATO, L.P.C. Nutrient cycling in two south-east brazilian forests I- Litterfall and litter standing crop. Journal Tropical Ecology, v. 8, p.205-205, 1992.

MURBACH M. R. et al. Nutrient cycling in a RRIM 600 clone rubber plantation. Piracicaba, SP. Scientia Agricola, Piracicaba, v. 60, n. 2, p. 353-357, abr./jun. 2003

PINTO, C. B.; MARQUES, R. Aporte de nutrientes por frações da serapilheira em sucessão ecológica de um ecossistema da floresta Atlântica. Floresta, Curitiba, v. 33, n. 3, p. 257-264, set./dez. 2003.

SAMPAIO, E. V. S. B.; NUNES, K. S.; LEMOS, E. P. Ciclagem de nutrientes na mata de Dois Irmãos (Recife - PE) através da queda de material vegetal. Pesquisa Agropecuária Brasileira, Brasília, v. 23, n. 10, p. 1055-1061, out. 1988.

SONGWE. N. C.; FASEHUN, F. E.; OKALI, D. U. U. Litterfall and productivity in a tropical rain forest, Southern Bankundu Forest, Cameroon. Journal of Tropical Ecology, Cambridge, v. 4, p.25-37, 1988.

TEDESCO, M. J. et al. Análise de solo, plantas e outros materiais. 2. ed. Porto Alegre: Departamento de Solos, UFRGS, 1995. $174 \mathrm{p}$.

TOLEDO, L. O.; PEREIRA, M. G.; MENEZES, C. E. G. Produção de serapilheira e transferência de nutrientes em florestas secundárias Localizadas na Região de Pinheiral, RJ. Ciência Florestal, Santa Maria, v. 12, n. 2, p. 9-16, jul./dez. 2002.

TOLEDO, L. O.; PEREIRA, M. G. dinâmica da deposição de serapilheira em florestas secundárias do município de Pinheiral, RJ. Floresta e Ambiente, Seropédica, v. 11, n. 1, p. 39-46, jan./jun. 2004.

UNESCO. Tropical forest ecosystems. A state of knowledge. Paris: UNEP/FAO, 1978. p. 233-88. (Natural Resources Research XIV).

VITAL, A. R. T. et al. Produção de serapilheira e ciclagem de nutrientes de uma floresta estacional semidecidual em zona ripária. Revista Árvore, Viçosa, v. 28, n. 6, p. 793-800, nov/dez. 2004.

WERNECK, M. S.; PEDRALLI, G.; GIESEKE, L. F. Produção de serrapilheira em três trechos de uma floresta semidecidual com diferentes graus de perturbação na Estação Ecológica de Tripuí, Ouro Preto, MG. Revista Brasileira de Botânica, São Paulo, v. 24, n. 2, p. 195-198, maio/ago. 2001. 